\title{
Early Discontinuation and Restart of Insulin in the Treatment of Type 2 Diabetes Mellitus
}

\author{
Haya Ascher-Svanum • Maureen J. Lage • \\ Magaly Perez-Nieves $\cdot$ Matthew D. Reaney $\cdot$ \\ Joanne Lorraine $\cdot$ Angel Rodriguez $\cdot$ Michael Treglia
}

To view enhanced content go to www.diabetestherapy-open.com

Received: January 28, 2014 / Published online: April 30, 2014

(c) The Author(s) 2014. This article is published with open access at Springerlink.com

\begin{abstract}
Introduction: Although the largest improvement in glycemic control occurs within the first 90 days of insulin therapy, little is known about early persistence on insulin therapy. This research aimed to identify predictors of early discontinuation and of subsequent restart of basal or mixture
\end{abstract}

Electronic supplementary material The online version of this article (doi:10.1007/s13300-014-0065-z) contains supplementary material, which is available to authorized users.

H. Ascher-Svanum · M. Perez-Nieves

Global Patient Outcomes and Real World Evidence,

Eli Lilly and Company, Indianapolis, IN, USA

M. J. Lage $(\bowtie) \cdot$ M. Treglia

HealthMetrics Outcomes Research, Bonita Springs,

FL, USA

e-mail: lagemj@hlthmetrics.com

M. D. Reaney

Eli Lilly and Company, Windlesham, Surrey, UK

Present Address:

M. D. Reaney

ERT, Peterborough Business Park, Lynch Wood,

Peterborough PE2 6FZ, UK

J. Lorraine

Eli Lilly Canada, Toronto, ON, Canada

A. Rodriguez

Eli Lilly Spain, Madrid, Spain insulin among patients with type 2 diabetes mellitus (T2DM) and to assess the economic cost associated with such behaviors over a 1-year period.

Methods: Truven's Health Analytics Commercial Claims and Encounters database was utilized for the study. Logistic regressions were used to examine factors associated with early discontinuation of insulin (basal or mixture) and, among patients who discontinued early, the factors associated with restarting. Cost regressions were estimated using generalized linear models with a gamma distribution and logistic link. Kaplan-Meier survival curves were used to examine time to discontinuation and time to restart among those who discontinued.

Results: Multivariate analyses revealed that patient characteristics, prior healthcare resource utilization, comorbid diagnoses, and type of initiated insulin were associated with early discontinuation of insulin and of restarting among patients who discontinued early. Acute care (hospitalization and emergency room) costs were 9.6\% higher among patients who discontinued early $(P<0.001)$, although outpatient, drug, and 
total costs were significantly lower among individuals who discontinued early. Among the early discontinuation subgroup, restarting insulin was associated with higher costs. Specifically: $11.3 \%$ higher acute care costs $(P<0.001), 24.0 \%$ higher outpatient costs $(P<0.001), 80.2 \%$ higher drug costs $(P<0.001)$, and $30.3 \%$ higher total costs $(P<0.001)$, compared to patients who discontinued early but did not restart insulin therapy in the 1-year post-period.

Conclusion: Among patients with T2DM who were initiated on insulin therapy, early discontinuation of insulin and its subsequent restart were associated with significantly higher acute care costs, which may signal a more complex and challenging subgroup of patients who tend to be less engaged in outpatient care and may have poorer long-term outcomes.

Keywords: Costs; Early discontinuation; Insulin; Persistence; Restart; Type 2 diabetes mellitus

\section{INTRODUCTION}

In the United States (US), an estimated 24.4 million adults aged $20-79$ years, or $10.90 \%$ of the population, have diabetes mellitus, with an additional $13.94 \%$ estimated to have impaired glucose tolerance [1]. The prevalence of diabetes is growing steeply, with some projections indicating that one in three Americans may have the disease by the year 2050 if recent incidence trends continue [2]. The impact of diabetes on the US economy is vast: the annual cost of the disease in 2012 was an estimated $\$ 245$ billion, comprising $\$ 176$ billion in direct medical costs and $\$ 69$ billion in decreased productivity [3]. Diabetes is currently the leading cause of kidney failure, lower-limb amputations (non-trauma related), and new cases of blindness among US adults, as well as one of the foremost causes of heart disease, stroke, and death [4]. The vast majority of individuals with diabetes (90-95\%) have type 2 diabetes mellitus (T2DM) [5], which is characterized by high blood glucose (hyperglycemia) in the context of insulin resistance and/or insulin deficiency [6].

Metformin therapy, in combination with lifestyle interventions, is the first line of treatment for T2DM [7]. However, many patients will ultimately require insulin therapy, either alone or in combination with other agents to maintain glucose control [8]. Insulin therapy is the oldest and most effective glucose-lowering treatment available [7], and patients with T2DM who start on insulin soon after the failure of oral antidiabetic drug (OAD) therapy have a greater likelihood of attaining the standard glycemic goal [glycated hemoglobin $(\mathrm{HbA1c})<7 \%$ ] relative to those whose insulin treatment is delayed $[9,10]$.

Previous research has highlighted the critical importance of maintaining persistence throughout the first several months of insulin drug therapy. Specifically, a recent study of patients with T2DM has demonstrated that the largest improvements in HbA1c occur within the first 90 days post-initiation of insulin [10]. However, some studies have indicated that when patients stop taking their antidiabetic medicines they do so approximately within the first 90 days [11, 12]. The likelihood of persistence with insulin therapy, in particular, throughout the first 90 days of post-initiation is currently unclear, as are the predictors and costs of early discontinuation.

To begin to address this information gap, the present retrospective study examined a US nationwide sample of patients with T2DM to identify observable characteristics associated with early discontinuation of basal or mixed insulin, and, among patients who discontinued 
early, the factors associated with restarting. In addition, using patients' cost data for the 12-month post-insulin initiation, this study quantified different types of medical costs associated with early discontinuation of insulin therapy and its subsequent restart.

\section{METHODS}

Data for this cohort study were obtained from the Truven Health Analytics Marketscan Commercial Claims and Encounters (CCAE) database. The CCAE database contains retrospective claims information on patient demographics, enrollment, inpatient, outpatient, and prescription drug use from a geographically diverse population living across the US. The data used spanned the period from January 1, 2008 through December 31, 2011 and were fully compliant with the Health Insurance Portability and Accountability Act. The analysis in this article is based on existing data, and does not involve any new studies of human or animal subjects performed by any of the authors.

To be included in this investigation, an individual had to have received a prescription for basal or mixture insulin between July 1, 2008 and January 1, 2011. The date of the first prescription was identified as the index date; patients were required to be at least 18 years old as of this date. They were also required to have been identified as having T2DM either through the coding of T2DM at least twice from 6 months before (the pre-period) to 12 months after the index date (the post-period), or, alternatively, through the coding of at least 1 diagnosis of T2DM and at least 1 prescription for an OAD. Patients were excluded from the study if they received a prescription for any insulin in the pre-period or for basal or mixture insulin with greater than or equal to 90 days' supply in the first 90 days of the post-period since there was no way to determine if such individuals discontinued early (within the first 90 days). Individuals were also excluded if they were diagnosed with gestational diabetes or pregnancy at any time from the start of the pre-period through the end of the post-period. Finally, participants were required to have preand post-period cost values greater than or equal to zero and to have continuous insurance coverage from the start of the preperiod through the end of the post-period.

The study focused on the factors associated with early discontinuation and the association between early discontinuation and medical costs, where early discontinuation was defined as a gap of at least 30 days between the end of 1 prescription (based upon fill date and days supplied) and the fill date for a subsequent prescription. Note that early discontinuation could be initiated by either the physician or the patient and the reason for such an action is unattainable in a claims database. In addition, among patients identified as early discontinuers, the factors associated with the restart of insulin therapy were examined, as were the associations between restarting insulin and medical costs. Restarting was defined as filling a prescription for insulin after a gap in insulin use of at least 30 days. All analyses controlled for patient characteristics, index medication prescribed, general health status, pre-period resource utilization, medication usage, and comorbidities. Patient characteristics included age, sex, region of residence, and type of insurance coverage. General health status and comorbidity burden were proxied by the Charlson Comorbidity Index (CCI) [13, 14]. Resource use in the preperiod included indicator variables for 
hospitalization or emergency room (ER) visits and total medical costs. Comorbid diagnoses identified in the pre-period included micro- and macrovascular complications, obesity, depression, dementia, alcohol abuse, and other mental health disorders. Pre-period medication use included any usage of an OAD, antidepressant, or other mental health-related medication as well as the total number of antidiabetic medications and all-cause drug classes prescribed. Index medication characteristics included human or analog, pen or vial, basal or mixture, and copayment amount.

Descriptive statistics (mean and standard deviation for continuous variables, and frequency and percentages for categorical variables) were used to characterize the sample; $t$ tests and Chi-square tests assessed differences between the cohorts. Separate logistic regressions examined the likelihood of being an early discontinuer and the likelihood of restarting insulin therapy among early discontinuers. In addition, general linear models with a gamma distribution and log link analyzed costs, where costs were proxied as gross payments to a provider for a service. The analyses focused on total medical as well as component costs, including: acute care (e.g., hospitalization and ER), outpatient, all-cause drug, and diabetes-related drug. All costs were measured over the entire 1-year post-period and were inflated to 2011 US dollars using the medical component of the consumer price index [15]. Kaplan-Meier curves also examined the time to discontinuation among all individuals and the time to restart among individuals who discontinued early. When examining time to discontinuation the analysis controlled for censoring among individuals who started a gap in therapy in the 11th month after the index date; such persons could not be identified as discontinuers since 30 days of data post-gap initiation was unavailable. Among the early discontinuation cohort, censoring controlled for the fact that the time from restart to the end of the postperiod differed across individuals.

To assess the robustness of the findings, all analyses were repeated four times. Specifically, the definition of discontinuation was modified from a minimum gap of 30 days to consider minimum gaps of 60 , 90, or 120 days. Furthermore, the analyses controlled for the possibility of sample selection among use of basal compared to mixed insulin by utilizing a Heckman two-stage sample selection model [16]. All analyses were conducted using SAS, version 9.3 (SAS Institute Inc., Cary, NC, USA). A $P$ value $<0.05$ was considered to be statistically significant.

\section{RESULTS}

The final sample consisted of 74,399 individuals and Table 1 illustrates how each of the inclusion and exclusion criteria affected sample size. Table 2 presents the descriptive statistics for the entire cohort. Results revealed that the mean patient age was 51.0 years (SD 9.0) years and that just over half of patients (54.0\%) were male. In addition, $45.5 \%$ resided in the South and $60.6 \%$ were insured via a preferred provider organization. Basal rather than mixture was more commonly the first insulin prescribed. Analog was more commonly prescribed than human insulin, and a pen was prescribed initially more frequently than a vial. A majority of patients received at least one OAD in the pre-period. Macrovascular complications were diagnosed in the pre-period for $16.5 \%$ of patients; mental health disorder in $11.1 \%$. 
Table 1 Inclusion-exclusion criteria and sample size

\section{Criteria}

Sample size

1. Initiation on basal or mixture insulin, with first such date identified as index date

707,143

2. No receipt of an insulin prescription with a day's supply of $\geq 90$ in first 90 days of post-period

537,556

3. No insulin use (basal, bolus, or mixture) in 6 months prior to index date (e.g., the pre-period)

479,475

4. No receipt of an insulin prescription with 0 days supply or missing days supply in the post-period

472,863

5. Age at least 18 on index date

455,740

6. Identified as having type 2 diabetes mellitus based upon either:

392,553

a. Receipt of at least two diagnoses of type 2 diabetes from start of the pre-period through 1-year post-index date (e.g., the post-period), or

b. Receipt of one diagnosis of type 2 diabetes from the start of the pre-period through the end of the post-period and receipt of an oral antidiabetic medication in the pre-period

7. No diagnosis of gestational diabetes or pregnancy at any time from the start of the pre-period through 382,412 the end of the post-period

8. Continuous insurance coverage from the start of the pre-period through 12 months post-index date

(e.g., the post-period)

9. Pre-period and post-period costs $\geq 0$

74,399

\section{Early Discontinuation}

A Kaplan-Meier survival curve shows time to discontinuation for the whole cohort (Fig. 1). After controlling for data censoring, Fig. 1 reveals that discontinuation occurred relatively early after initiation of insulin. Specifically, the estimated probability of discontinuation was $82.0 \%$ in the first year, $61.5 \%$ in the first 90 days, and $41.0 \%$ in the first 31 days.

Table 2 also shows descriptive characteristics based on early discontinuation status. Patients who discontinued early, compared to those who did not, were significantly younger, as well as more likely to be female and to reside in the South. Furthermore, early discontinuers were significantly more likely to be initiated on basal insulin and a pen. Early discontinuers were significantly more likely in the pre-period to have had a hospital stay, an ER visit, and higher mean total medical costs. However, on average, patients who did not discontinue early used more types of antidiabetic and all-cause medications; they also had greater use of antidepressants, and psychiatric medication and a higher prevalence of macrovascular complications.

Table 3 examines factors associated with a change in the likelihood of early discontinuation. Results revealed that observable factors, such as patient characteristics, type of index medication prescribed, prior resource use, comorbid conditions and other medications prescribed all were associated with changes in the likelihood of early discontinuation. Older age, and residence in the Northeast, the North Central region, or the West, as compared to the South, were associated with a lower likelihood of early discontinuation. Females 
Table 2 Descriptive statistics-entire cohort and by early discontinuation status

\begin{tabular}{|c|c|c|c|c|c|c|c|}
\hline & \multicolumn{2}{|c|}{$\begin{array}{l}\text { Entire sample } \\
(N=74,399)\end{array}$} & \multicolumn{2}{|c|}{$\begin{array}{l}\text { No early } \\
\text { discontinuation } \\
(N=28,667)\end{array}$} & \multicolumn{2}{|c|}{$\begin{array}{l}\text { Early } \\
\text { discontinuation } \\
(N=45,732)\end{array}$} & \multirow[t]{2}{*}{$P$ value } \\
\hline & $N$ or mean & $\%$ or SD & $N$ or mean & $\%$ or $\mathrm{SD}$ & $N$ or mean & $\%$ or $\mathrm{SD}$ & \\
\hline \multicolumn{8}{|l|}{ Patient characteristics } \\
\hline Age (mean; SD) & 51.0 & 9.0 & 51.7 & 8.7 & 50.5 & 9.2 & $<0.001$ \\
\hline Sex & & & & & & & $<0.001$ \\
\hline Male & 40,197 & 54.0 & 15,883 & 55.4 & 24,314 & 53.2 & \\
\hline Female & 34,202 & 46.0 & 12,784 & 44.6 & 21,418 & 46.8 & \\
\hline Region & & & & & & & $<0.001$ \\
\hline Northeast & 9,856 & 13.3 & 4,202 & 14.7 & 5,654 & 12.4 & \\
\hline North Central & 18,054 & 24.3 & 7,324 & 25.6 & 10,730 & 23.5 & \\
\hline South & 33,816 & 45.5 & 12,228 & 42.7 & 21,588 & 47.2 & \\
\hline West & 11,330 & 15.2 & 4,394 & 15.3 & 6,936 & 15.2 & \\
\hline Unknown & 1,343 & 1.8 & 519 & 1.8 & 824 & 1.8 & \\
\hline Insurance plan type & & & & & & & $<0.001$ \\
\hline Comprehensive & 1,826 & 2.5 & 741 & 2.6 & 1,085 & 2.4 & \\
\hline Exclusive provider organization & 835 & 1.1 & 309 & 1.1 & 526 & 1.2 & \\
\hline Health maintenance organization & 12,858 & 17.3 & 4,686 & 16.4 & 8,172 & 17.9 & \\
\hline Point of service & 5,919 & 8.0 & 2,246 & 7.8 & 3,673 & 8.0 & \\
\hline Preferred provider organization & 45,048 & 60.6 & 17,418 & 60.8 & 27,630 & 60.4 & \\
\hline Point of service with capitation & 341 & 0.5 & 129 & 0.5 & 212 & 0.5 & \\
\hline Consumer-directed health plan & 2,214 & 3.0 & 919 & 3.2 & 1,295 & 2.8 & \\
\hline High deductible health plan & 917 & 1.2 & 379 & 1.3 & 538 & 1.2 & \\
\hline Unknown & 4,441 & 6.0 & 1,840 & 6.4 & 2,601 & 5.7 & \\
\hline \multicolumn{8}{|l|}{ Index medication } \\
\hline Human vs. analog & & & & & & & 0.160 \\
\hline Analog & 67,118 & 90.2 & 25,917 & 90.4 & 41,201 & 90.1 & \\
\hline Human & 7,281 & 9.8 & 2,750 & 9.6 & 4,531 & 9.9 & \\
\hline Basal vs. mixture & & & & & & & $<0.001$ \\
\hline Basal & 65,990 & 88.7 & 25,063 & 87.4 & 40,927 & 89.5 & \\
\hline Mixture & 8,409 & 11.3 & 3,604 & 12.6 & 4,805 & 10.5 & \\
\hline Administration mode & & & & & & & $<0.001$ \\
\hline Pen & 44,065 & 59.2 & 16,101 & 56.2 & 27,964 & 61.2 & \\
\hline
\end{tabular}


Table 2 continued

\begin{tabular}{|c|c|c|c|c|c|c|c|}
\hline & \multicolumn{2}{|c|}{$\begin{array}{l}\text { Entire sample } \\
(N=74,399)\end{array}$} & \multicolumn{2}{|c|}{$\begin{array}{l}\text { No early } \\
\text { discontinuation } \\
(N=28,667)\end{array}$} & \multicolumn{2}{|c|}{$\begin{array}{l}\text { Early } \\
\text { discontinuation } \\
(N=45,732)\end{array}$} & \multirow[t]{2}{*}{$P$ value } \\
\hline & $N$ or mean & $\%$ or $\mathrm{SD}$ & $N$ or mean & $\%$ or $\mathrm{SD}$ & $N$ or mean & $\%$ or $\mathrm{SD}$ & \\
\hline Vial & 30,334 & 40.8 & 12,566 & 43.8 & 17,768 & 38.9 & \\
\hline Copayment (mean; SD) & 26.7 & 27.4 & 26.2 & 25.8 & 27.1 & 28.3 & $<0.001$ \\
\hline \multicolumn{8}{|l|}{ Pre-period variables } \\
\hline $\begin{array}{l}\text { Charlson comorbidity index } \\
\text { (mean; SD) }\end{array}$ & 1.7 & 1.4 & 1.7 & 1.4 & 1.7 & 1.4 & 0.195 \\
\hline Hospitalized & 16,626 & 22.4 & 6,241 & 21.8 & 10,385 & 22.7 & 0.003 \\
\hline Emergency room visit & 22,270 & 29.9 & 8,256 & 28.8 & 14,014 & 30.6 & $<0.001$ \\
\hline Use of oral antidiabetic medication & 50,992 & 68.5 & 20,075 & 70.0 & 30,917 & 67.6 & $<0.001$ \\
\hline $\begin{array}{l}\text { Number of antidiabetic medication } \\
\text { classes (mean; SD) }\end{array}$ & 1.9 & 1.5 & 2.0 & 1.5 & 1.8 & 1.4 & $<0.001$ \\
\hline $\begin{array}{l}\text { Number of all-cause medication } \\
\text { classes (mean; SD) }\end{array}$ & 6.5 & 4.4 & 6.7 & 4.5 & 6.3 & 4.3 & $<0.001$ \\
\hline Microvascular complication & 5,276 & 7.1 & 2,057 & 7.2 & 3,219 & 7.0 & 0.480 \\
\hline Macrovascular complication & 12,290 & 16.5 & 4,918 & 17.2 & 7,372 & 16.1 & $<0.001$ \\
\hline Depression & 2,609 & 3.5 & 1,006 & 3.5 & 1,603 & 3.5 & 0.977 \\
\hline Obesity & 5,955 & 8.0 & 2,361 & 8.2 & 3,594 & 7.9 & 0.065 \\
\hline Dementia & 51 & 0.1 & 15 & 0.1 & 36 & 0.1 & 0.181 \\
\hline Alcohol use disorder & 595 & 0.8 & 228 & 0.8 & 367 & 0.8 & 0.915 \\
\hline Mental health disorder & 8,224 & 11.1 & 3,141 & 11.0 & 5,083 & 11.1 & 0.504 \\
\hline Use of antidepressant & 14,995 & 20.2 & 6,381 & 22.3 & 8,614 & 18.8 & $<0.001$ \\
\hline Psychiatric medication use & 14,476 & 19.5 & 5,752 & 20.1 & 8,724 & 19.1 & $<0.001$ \\
\hline Total healthcare costs (mean; SD) & 13,963 & 42,048 & 13,391 & 38,206 & 14,322 & 44,284 & 0.002 \\
\hline
\end{tabular}

were more likely to be early discontinuers compared to males, as were patients insured with a health maintenance compared to a preferred provider organization. When examining the index prescription of insulin, results revealed that patients who were prescribed analog rather than human insulin, a vial instead of a pen, or mixture instead of basal were significantly less likely to be early discontinuers.

Table 3 also shows that the pre-period variables associated with a higher likelihood of early discontinuation were: visits to the ER, higher total costs, receipt of an $\mathrm{OAD}$, or a diagnosis of comorbid depression. In contrast, a comorbid diagnosis of obesity was associated 


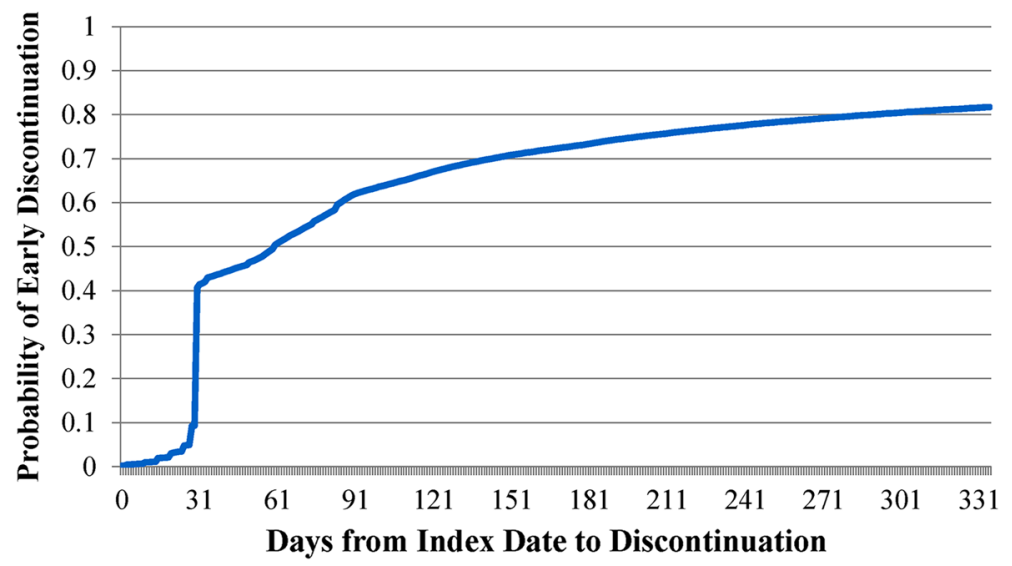

Fig. 1 Kaplan-Meier estimates of the cumulative probability of discontinuation

Table 3 Logistic regression-predictors of early discontinuation

\begin{tabular}{|c|c|c|c|c|}
\hline & \multirow[t]{2}{*}{ Odds ratio } & \multicolumn{2}{|c|}{$95 \%$ confidence interval } & \multirow[t]{2}{*}{$P$ value } \\
\hline & & Lower & Upper & \\
\hline \multicolumn{5}{|l|}{ Patient characteristics } \\
\hline Age & 0.99 & 0.99 & 0.99 & $<0.001$ \\
\hline Female $^{a}$ & 1.13 & 1.09 & 1.16 & $<0.001$ \\
\hline Northeast ${ }^{\mathrm{b}}$ & 0.75 & 0.72 & 0.78 & $<0.001$ \\
\hline North Central ${ }^{\mathrm{b}}$ & 0.84 & 0.81 & 0.87 & $<0.001$ \\
\hline West $^{\mathrm{b}}$ & 0.91 & 0.87 & 0.95 & $<0.001$ \\
\hline Health maintenance organization ${ }^{c}$ & 1.12 & 1.07 & 1.17 & $<0.001$ \\
\hline Point of service ${ }^{c}$ & 1.05 & 0.99 & 1.11 & 0.095 \\
\hline Other health insurance ${ }^{c}$ & 0.97 & 0.91 & 1.02 & 0.239 \\
\hline \multicolumn{5}{|l|}{ Pre-period } \\
\hline Charlson comorbidity index & 1.01 & 1.00 & 1.02 & 0.121 \\
\hline Hospitalized & 1.01 & 0.96 & 1.06 & 0.758 \\
\hline Emergency room visit & 1.08 & 1.04 & 1.13 & $<0.001$ \\
\hline Total costs & 1.01 & 1.00 & 1.01 & $<0.001$ \\
\hline Microvascular complication & 1.03 & 0.97 & 1.09 & 0.367 \\
\hline Macrovascular complication & 0.99 & 0.94 & 1.03 & 0.507 \\
\hline Depression & 1.10 & 1.01 & 1.20 & 0.029 \\
\hline Obesity & 0.92 & 0.87 & 0.98 & 0.006 \\
\hline Dementia & 1.52 & 0.83 & 2.80 & 0.179 \\
\hline Alcohol use disorder & 0.97 & 0.82 & 1.15 & 0.753 \\
\hline
\end{tabular}


Table 3 continued

\begin{tabular}{|c|c|c|c|c|}
\hline & \multirow[t]{2}{*}{ Odds ratio } & \multicolumn{2}{|c|}{$95 \%$ confidence interval } & \multirow[t]{2}{*}{$P$ value } \\
\hline & & Lower & Upper & \\
\hline Mental health disorder & 1.05 & 1.00 & 1.10 & 0.071 \\
\hline Use of oral antidiabetic medication & 1.13 & 1.08 & 1.18 & $<0.001$ \\
\hline Number of antidiabetic medications classes & 0.92 & 0.90 & 0.93 & $<0.001$ \\
\hline Number of classes of all-cause medications & 0.99 & 0.98 & 0.99 & $<0.001$ \\
\hline Use of antidepressant & 0.84 & 0.80 & 0.87 & $<0.001$ \\
\hline Use of other mental health medications & 1.04 & 1.00 & 1.09 & 0.060 \\
\hline \multicolumn{5}{|l|}{ Index prescription } \\
\hline Analog ${ }^{\mathrm{d}}$ & 0.78 & 0.74 & 0.83 & $<0.001$ \\
\hline Vial $^{\mathrm{e}}$ & 0.73 & 0.71 & 0.75 & $<0.001$ \\
\hline Mixture $^{f}$ & 0.74 & 0.70 & 0.78 & $<0.001$ \\
\hline Copayment & 1.00 & 1.00 & 1.00 & 0.187 \\
\hline
\end{tabular}

Reference categories: ${ }^{a}$ male, ${ }^{b}$ South, ${ }^{c}$ preferred provider organization, ${ }^{d}$ human insulin, ${ }^{\mathrm{e}}$ pen, basal insulin

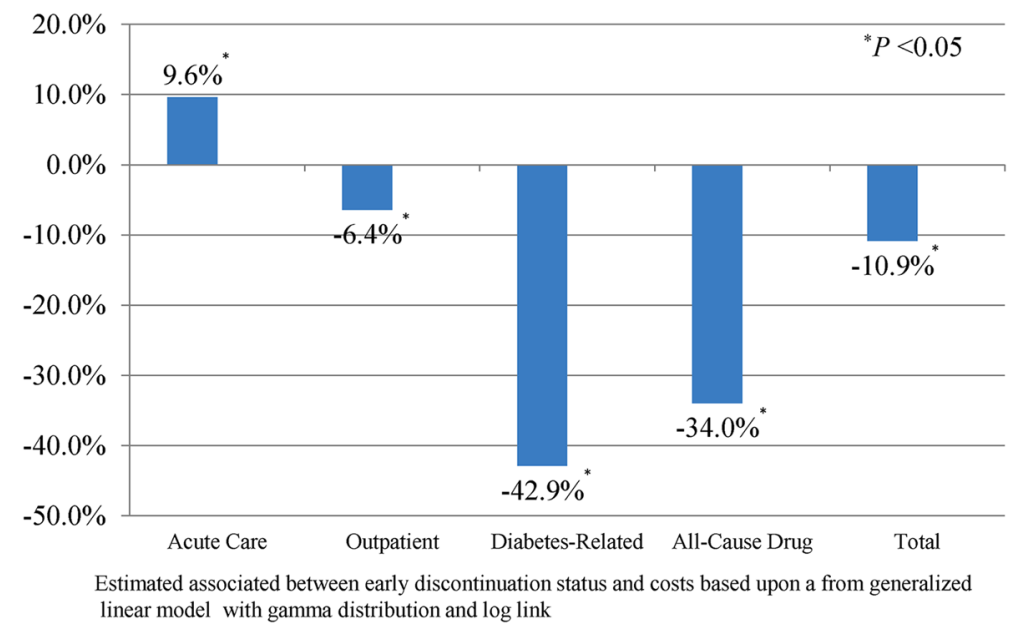

Fig. 2 Association between early discontinuation and costs estimated percentage change in costs associated with early discontinuation

with a significantly lower likelihood of early discontinuation, as was the use of more antidiabetic medications, more classes of medications for any cause, or an antidepressant.

Figure 2 examines the association between early discontinuation and costs, after controlling for patient characteristics, index medication prescribed, general health, preperiod comorbidities, resource utilization, and medication usage. Given that we used a generalized linear model with a gamma distribution and log link, the exponentiated coefficient associated with early discontinuation $\left(\mathrm{e}^{\beta}\right)$ could be easily interpreted 
[17] and provided the proportional change in costs for each covariate [18]. Results revealed that early discontinuation was associated with $9.6 \%$ significantly higher acute care costs $(P<0.0001)$ and significantly lower outpatient, diabetes drug, all-cause drug, and total costs.

\section{Restarting Insulin Therapy}

Figure 3 examines the cumulative probability of restarting insulin therapy among those who discontinued early. Results revealed that, among those who discontinued early, there was a $90.3 \%$ probability of restarting within the first year post-initiation. The probability of restarting within 3 months of discontinuation was $55.3 \%$, while the probability of restarting within 6 months was $77.5 \%$. Among those who restarted, the average time between discontinuation and restart was 160 days (SD 82.0 days). During this time period, $57.5 \%$ of patients received a prescription for an $\mathrm{OAD}$, while $3.7 \%$ received a prescription for both an $\mathrm{OAD}$ and an injectable non-insulin antidiabetic agent; $37.8 \%$ received no antidiabetic medication.

Among the early discontinuers, there were a number of statistically significant differences between those who restarted insulin therapy and those who did not (Table 4). Specifically, patients who restarted were older and less likely to reside in the South. Furthermore, patients who restarted insulin therapy were significantly more likely to have had an index prescription for analog compared to human insulin, basal relative to mixture and pens rather than vials. Finally, patients who restarted were less likely to have had a pre-period hospitalization or ER visit and, in the pre-period, they also had lower total medical costs.

Table 5 examines factors associated with a change in the likelihood of restarting insulin from multivariable analysis. Consistent with the unadjusted statistics presented in Table 4, factors associated with a higher likelihood of restarting insulin within the 1-year period of observation were: being older, being female, and residing in the North Central US rather than the South. Factors associated with a lower likelihood of restarting were: using a vial rather than a pen, using mixture rather than basal, and having a higher index medication copayment. Patients with more pre-period hospitalizations or ER visits were also less likely to restart insulin therapy, while those who, in the pre-period, used more medications in general or more

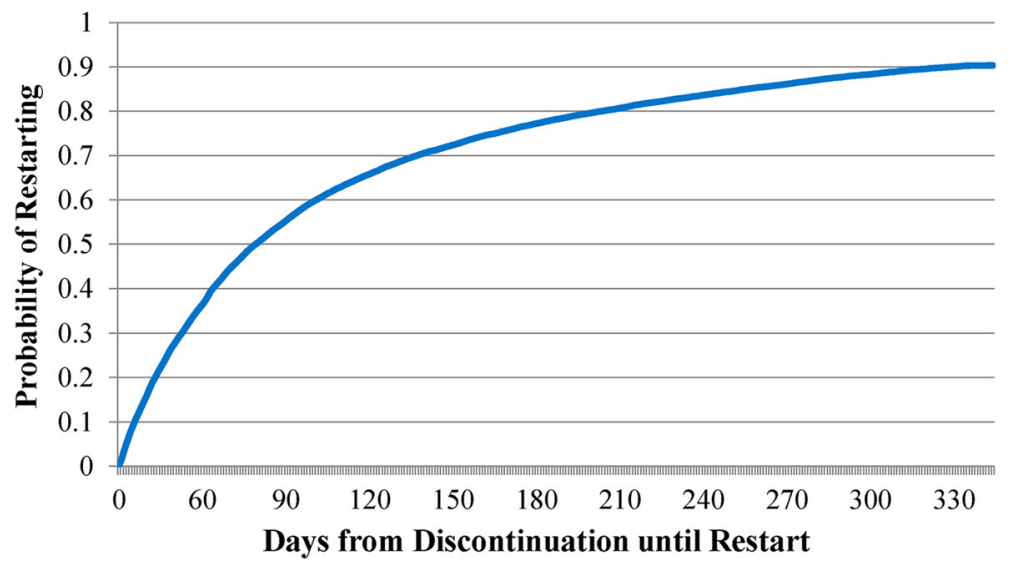

Fig. 3 Kaplan-Meier estimates of the cumulative probability of restarting among early discontinuers 
Table 4 Descriptive statistics for early discontinuers-by restart status

\begin{tabular}{|c|c|c|c|c|c|}
\hline & \multicolumn{2}{|c|}{ No restart $(N=4,422)$} & \multicolumn{2}{|c|}{ Restart $(N=41,310)$} & \multirow[t]{2}{*}{$P$ value } \\
\hline & $N$ or mean & $\%$ or $S D$ & $N$ or mean & $\%$ or $\mathrm{SD}$ & \\
\hline \multicolumn{6}{|l|}{ Patient characteristics } \\
\hline Age (mean; SD) & 49.1 & 9.7 & 50.7 & 9.1 & $<0.001$ \\
\hline Sex & & & & & $<0.001$ \\
\hline Male & 2,513 & 56.8 & 21,801 & 52.8 & \\
\hline Female & 1,909 & 43.2 & 19,509 & 47.2 & \\
\hline Region & & & & & 0.001 \\
\hline Northeast & 537 & 12.1 & 5,117 & 12.4 & \\
\hline North Central & 947 & 21.4 & 9,783 & 23.7 & \\
\hline South & 2,181 & 49.3 & 19,407 & 47.0 & \\
\hline West & 652 & 14.7 & 6,284 & 15.2 & \\
\hline Unknown & 105 & 2.4 & 719 & 1.7 & \\
\hline Insurance plan type & & & & & 0.070 \\
\hline Comprehensive & 99 & 2.2 & 986 & 2.4 & \\
\hline Exclusive provider organization & 45 & 1.0 & 481 & 1.2 & \\
\hline Health maintenance organization & 733 & 16.6 & 7,439 & 18.0 & \\
\hline Point of service & 351 & 7.9 & 3,322 & 8.0 & \\
\hline Preferred provider organization & 2,739 & 61.9 & 24,891 & 60.3 & \\
\hline Point of service with capitation & 16 & 0.4 & 196 & 0.5 & \\
\hline Consumer-directed health plan & 119 & 2.7 & 1,176 & 2.9 & \\
\hline High deductible health plan & 68 & 1.5 & 470 & 1.1 & \\
\hline Unknown & 252 & 5.7 & 2,349 & 5.7 & \\
\hline \multicolumn{6}{|l|}{ Index medication } \\
\hline Human vs. analog & & & & & $<0.001$ \\
\hline Analog & 3,895 & 88.1 & 37,306 & 90.3 & \\
\hline Human & 527 & 11.9 & 4,004 & 9.7 & \\
\hline Basal vs. mixture & & & & & $<0.001$ \\
\hline Basal & 3,819 & 86.4 & 37,108 & 89.8 & \\
\hline Mixture & 603 & 13.6 & 4,202 & 10.2 & \\
\hline Administration mode & & & & & $<0.001$ \\
\hline Pen & 2,159 & 48.8 & 25,805 & 62.5 & \\
\hline Vial & 2,263 & 51.2 & 15,505 & 37.5 & \\
\hline Copayment (mean; SD) & 29.3 & 44.7 & 26.8 & 25.9 & $<0.001$ \\
\hline
\end{tabular}


Table 4 continued

\begin{tabular}{|c|c|c|c|c|c|}
\hline & \multicolumn{2}{|c|}{ No restart $(N=4,422)$} & \multicolumn{2}{|c|}{ Restart $(N=41,310)$} & \multirow[t]{2}{*}{$P$ value } \\
\hline & $N$ or mean & $\%$ or $\mathrm{SD}$ & $N$ or mean & $\%$ or $S D$ & \\
\hline \multicolumn{6}{|l|}{ Pre-period variables } \\
\hline Charlson comorbidity index (mean; SD) & 1.7 & 1.6 & 1.63 & 1.4 & $<0.001$ \\
\hline Hospitalized & 1,564 & 35.4 & 8,821 & 21.4 & $<0.001$ \\
\hline Emergency room visit & 1,830 & 41.4 & 12,184 & 29.5 & $<0.001$ \\
\hline Receipt of oral medication & 2,254 & 51.0 & 28,663 & 69.4 & $<0.001$ \\
\hline Number of antidiabetic medication classes (mean; SD) & 1.3 & 1.3 & 1.9 & 1.4 & $<0.001$ \\
\hline Number of all-cause medication classes (mean; SD) & 5.1 & 4.3 & 6.4 & 4.3 & $<0.001$ \\
\hline Microvascular complication & 278 & 6.3 & 2,941 & 7.1 & 0.040 \\
\hline Macrovascular complication & 839 & 19.0 & 6,533 & 15.8 & $<0.001$ \\
\hline Depression & 144 & 3.3 & 1,459 & 3.6 & 0.344 \\
\hline Obesity & 467 & 10.6 & 3,127 & 7.6 & $<0.001$ \\
\hline Dementia & 5 & 0.1 & 31 & 0.1 & 0.392 \\
\hline Alcohol use disorder & 59 & 1.3 & 308 & 0.8 & $<0.001$ \\
\hline Mental health disorder & 585 & 13.2 & 4,498 & 10.9 & $<0.001$ \\
\hline Use of antidepressant & 611 & 13.8 & 8,003 & 19.4 & $<0.001$ \\
\hline Psychiatric medication use & 736 & 16.6 & 7,998 & 19.3 & $<0.001$ \\
\hline Total costs (mean; SD) & 21,454 & 68,454 & 13,559 & 40,786 & $<0.001$ \\
\hline
\end{tabular}

antidiabetic medications in particular were more likely to restart their insulin therapy.

Figure 4 examines the association between restarting and total costs over the 1-year postperiod, including periods of treatment with insulin and periods of treatment without insulin, among those who discontinued early. After controlling for patient characteristics, index medication, general health, medications prescribed, and comorbidities among the early discontinuers, our analyses revealed that those who restarted insulin had significantly higher medical costs than those who did not. Specifically, relative to the early discontinuers who did not restart, the restarters had higher costs in all of the following areas: acute care
(11.3\%; $\quad P<0.001), \quad$ outpatient $\quad$ (24.0\%; $P<0.001)$ diabetes-related drug $\quad(112.9 \%$; $P<0.001)$, all-cause drug (80.2\%; $P<0.001)$, and total medical (30.3\%; $P<0.001)$.

\section{Sensitivity of Results}

Results from the multiple sensitivity analyses revealed few differences compared to the main results reported. As expected, both the probability of discontinuation and the odds of restarting declined as the length of the minimum gap in therapy required to be defined as a discontinuer increased from 30 to 60,90 , or 120 days. As the duration of gap days required for discontinuation increased, the 
Table 5 Logistic regression-predictors of restart among early discontinuers

\begin{tabular}{|c|c|c|c|c|}
\hline & \multirow[t]{2}{*}{ Odds ratio } & \multicolumn{2}{|c|}{$95 \%$ confidence interval } & \multirow[t]{2}{*}{$P$ value } \\
\hline & & Lower & Upper & \\
\hline \multicolumn{5}{|l|}{ Patient characteristics } \\
\hline Age & 1.01 & 1.01 & 1.01 & $<0.001$ \\
\hline Female $^{\mathrm{a}}$ & 1.07 & 1.00 & 1.14 & 0.041 \\
\hline Northeast region $^{\mathrm{b}}$ & 1.06 & 0.95 & 1.17 & 0.301 \\
\hline North Central region ${ }^{\mathrm{b}}$ & 1.16 & 1.07 & 1.26 & $<0.001$ \\
\hline West region ${ }^{\mathrm{b}}$ & 1.03 & 0.93 & 1.13 & 0.574 \\
\hline Health maintenance organization ${ }^{c}$ & 1.07 & 0.98 & 1.17 & 0.152 \\
\hline Point of service ${ }^{c}$ & 1.02 & 0.90 & 1.14 & 0.808 \\
\hline Other health insurance ${ }^{c}$ & 0.97 & 0.86 & 1.10 & 0.619 \\
\hline \multicolumn{5}{|l|}{ Pre-period } \\
\hline Charlson comorbidity index & 0.98 & 0.96 & 1.01 & 0.160 \\
\hline Hospitalized & 0.68 & 0.62 & 0.75 & $<0.001$ \\
\hline Emergency room visit & 0.88 & 0.81 & 0.95 & 0.002 \\
\hline Total costs & 0.99 & 0.98 & 1.00 & $<0.001$ \\
\hline Microvascular complication & 1.20 & 1.05 & 1.37 & 0.006 \\
\hline Macrovascular complication & 1.01 & 0.91 & 1.11 & 0.921 \\
\hline Depression & 1.18 & 0.98 & 1.42 & 0.077 \\
\hline Obesity & 0.87 & 0.78 & 0.97 & 0.015 \\
\hline Dementia & 0.98 & 0.37 & 2.57 & 0.960 \\
\hline Alcohol use disorder & 0.90 & 0.67 & 1.21 & 0.485 \\
\hline Mental health disorder & 0.92 & 0.83 & 1.02 & 0.099 \\
\hline Use of oral antidiabetic medication & 1.19 & 1.07 & 1.31 & $<0.001$ \\
\hline Number of antidiabetic medications classes & 1.11 & 1.07 & 1.16 & $<0.001$ \\
\hline Number of classes of all-cause medications & 1.04 & 1.03 & 1.05 & $<0.001$ \\
\hline Use of antidepressant & 1.12 & 1.01 & 1.24 & 0.034 \\
\hline Use of other mental health medications & 0.95 & 0.87 & 1.05 & 0.343 \\
\hline \multicolumn{5}{|l|}{ Index prescription } \\
\hline Analog ${ }^{\mathrm{d}}$ & 0.90 & 0.80 & 1.00 & 0.058 \\
\hline $\mathrm{Vial}^{\mathrm{e}}$ & 0.70 & 0.66 & 0.75 & $<0.001$ \\
\hline Mixture $^{\mathrm{f}}$ & 0.80 & 0.73 & 0.89 & $<0.001$ \\
\hline Copayment & 1.00 & 1.00 & 1.00 & 0.001 \\
\hline
\end{tabular}

Reference categories: ${ }^{\mathrm{a}}$ male, ${ }^{\mathrm{b}}$ South, ${ }^{\mathrm{c}}$ preferred provider organization, ${ }^{\mathrm{d}}$ human insulin, ${ }^{\mathrm{e}} \mathrm{pen}$ 


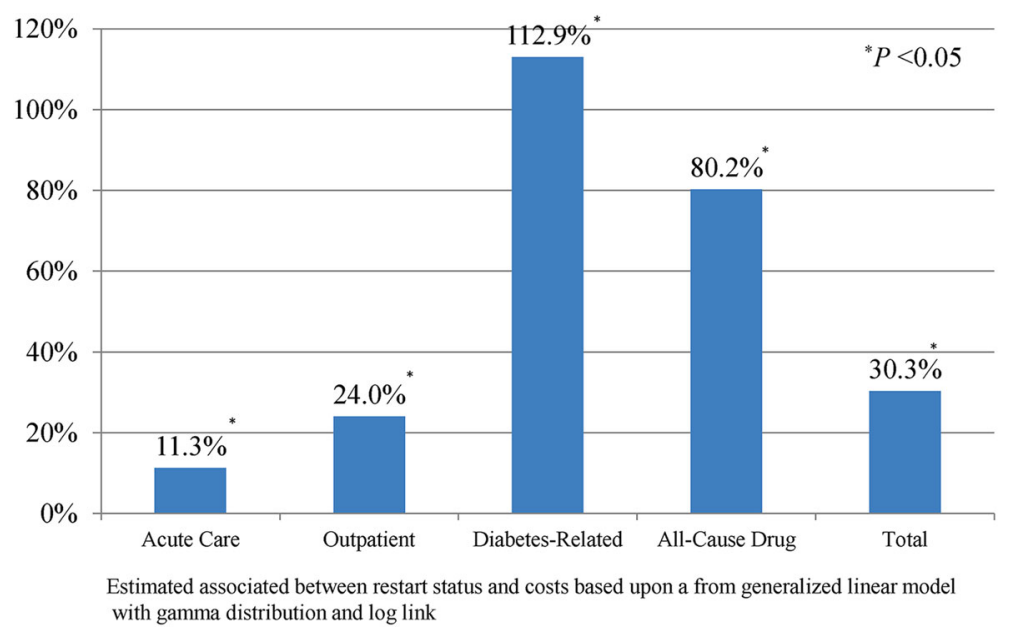

Fig. 4 Association between restart and costs among early discontinuers-estimated percentage change in costs associated with restart

estimated association between early 31 days. These results highlight the importance discontinuation and all costs (acute care, outpatient, diabetes drug, all-cause drug, and total) became greater. Among those who discontinued early, as the gap in days required to be identified as a discontinuer grew, the association between restart and acute care costs increased. However, the association between restart and outpatient, diabetes drug, all-cause drug, and total costs all decreased. Note though, that in all cases, there was no change in either the sign or the statistical significance associated with the main analyses. Likewise, the sample selection model revealed little difference compared to the main analyses reported.

\section{DISCUSSION}

Consistent with earlier studies of persistence with antidiabetic treatments of various kinds $[11,12,19]$, this examination of basal and mixture insulin initiators found that early discontinuation is prevalent. Indeed, the probability of discontinuation of insulin in the first 90 days was $61.5 \%$, with a $41.0 \%$ probability of discontinuation within the first of the first 90 days of therapy from both the clinician and payer perspectives. Moreover, these findings elucidate the need to assess restart of the treatment among patients who have discontinued early. Notably, focusing only on early discontinuation in the present study would have provided a partial and inaccurate picture of the true insulin therapy attrition rate, given the $90.3 \%$ probability of restarting during the first year post-initiation.

\section{Identifying Early Discontinuers and Restarters}

This study revealed a distinct set of identifiable predictors that may help recognize early discontinuers and non-restarters even prior to initiating insulin therapy. This information may help target these patients for adherence/ persistence interventions, which may in turn help reduce the use and cost of acute care (hospitalization and ER) and improve patients' long-term outcomes. In particular, the early discontinuers in this study, compared to the patients who persisted on therapy past the first 
90 days, appeared to be less engaged in outpatient care, as indicated by their lower outpatient costs and greater likelihood of preperiod ER use. These findings are consistent with previous research linking greater outpatient engagement with improvement in glycemic control [20].

In addition, while patients diagnosed with depression were more likely to discontinue early, those prescribed an antidepressant were less likely to discontinue early. These findings further highlight the importance of outpatient care and are consistent with previous research showing an association between comorbid depression and poor adherence among patients with T2DM [21], as well as with studies showing that medication adherence and glycemic outcomes improve among patients with T2DM when their depression is treated [22].

\section{Early Discontinuers are Likely to Restart Insulin Therapy}

Among early discontinuers, the probability of restarting therapy in the post-period was high (90.3\%), pointing not only to a low treatment attrition rate but also to the realization that early discontinuation appears to reflect a temporary interruption of the long-term treatment process rather than a true and complete cessation. The probability of restarting was $55.3 \%$ within 3 months of the discontinuation date and $77.5 \%$ within 6 months. Importantly, an earlier study, which looked at persistence over a 10-year period, found similar results: most patients (57.9\%) discontinued antidiabetic drug treatment at some point over the decade, but most discontinuers restarted, with only $8-10 \%$ of insulin users discontinuing and never restarting [19]. Moreover, the earlier study also reported that most discontinuers lapsed earlyin that investigation within the first year postdiagnosis-and that after restarting generally did not lapse again throughout the decade [19]. Taken together, the evidence from the present study and the earlier investigation may be useful not only for motivating better persistence on insulin but also for setting realistic treatment expectations.

\section{High Burden of Early Discontinuation and Restart}

Our study exposed another strong incentive for maintaining persistence on insulin therapy: early discontinuation and restart of insulin are associated with adverse economic and humanistic ramifications. Compared to nonearly discontinuation, early discontinuation was associated with significantly greater acute care costs. In particular, the early discontinuers had $9.6 \%$ higher acute care costs compared to the patients who did not discontinue early. As it has been argued previously, it is important in the treatment of chronic disease to go beyond assessing patients' total medical costs and to distinguish between expectable and unexpectable medical costs [23]. Expectable costs are those incurred to support comprehensive and continuous care and tend to reflect patients' engagement in their treatment. Such costs often include routine outpatient care, medications, and various medical tests and supplies and may be justifiable in light of the considerable intangible costs (e.g., human suffering) prevented [23]. In contrast, unexpectable costs are those incurred for acute or intensive care, such as ER services and hospitalization. Such costs are potentially modifiable and avoidable and are often linked to poorer long-term treatment outcomes. 
Finally, the present study revealed that restarting insulin therapy provided no mitigation of the higher costs linked to early discontinuation. Indeed, the direct costs of the restarters were higher than those of non-restarting early discontinuers, both in total and in component costs, including those associated with acute care. It may be that a hospitalization or an ER visit was the precipitating event for the restart of insulin. A large body of literature on T2DM has likewise shown a link between poor adherence and worse outcomes, including an increased risk of hospitalization [24-29].

\section{Limitations}

The results of this study should be viewed in the context of its potential limitations. First, the analyses were based on observational healthclaims data which may affect the generalizability of the results. For instance, the analysis included only individuals with continuous medical and prescription benefit coverage over an 18-month period and excluded patients who received a 3-month or greater supply of insulin with their initial prescription, since there was no way to determine whether such patients discontinued early. Second, the use of diagnostic codes is not as rigorous as formal assessments for identifying patients with T2DM, and may under-represent certain conditions, such as obesity or alcohol abuse. Third, the use of claims data precluded an examination of associations between health outcomes and factors such as race, body mass index, or duration of diabetes. Fourth, the dataset did not allow for a study of the causes of discontinuation or restart; for instance, neither the initiator (physician or patient) nor the reason for the discontinuation or restart could be determined. Fifth, the follow-up period was relatively short and, hence, did not allow for investigation of whether secondary or primary persistence was better in restarters. Finally, the analysis focused on statistical significance and is unable to determine whether differences in outcomes represent minimal clinically important differences. Given these limitations, we believe that these results should be generally representative of clinical practice, as the Truven Health Analytics Marketscan CCAE database contains information from a large, geographically diverse US population. Furthermore, results reported here were generally consistent with alternative models which controlled for sample selection and allowed for at least a 60, 90, or 120-day gap in insulin therapy before identifying a patient as having discontinued.

\section{CONCLUSION}

In this study of patients with T2DM who were initiated on insulin therapy, more than half discontinued within the first 3 months but almost all of these early discontinuers restarted therapy a few months later. These findings highlight the importance of the first 90 days of insulin therapy and the need to go beyond routine assessment of persistence and also to capture restart of therapy, which appears to be highly prevalent. This study identified specific predictors of early discontinuation and restart of insulin, and thus may enable timely identification of patients for targeted interventions that could improve persistence, reduce healthcare costs, and improve long-term outcomes. Furthermore, early discontinuation and restart of insulin therapy appear to be associated with significantly higher acute care (hospitalization and ER) costs that are potentially avoidable and may signal a more complex and challenging subgroup of patients who tend to be less engaged in outpatient care and have poorer long-term outcomes. 


\section{ACKNOWLEDGMENTS}

Patricia Platt assisted in the writing of the manuscript and Joyce Healey, from Words With Joyce, LLC, assisted in the editing of this manuscript. Patricia Platt and Joyce Healey were compensated by HealthMetrics Outcomes research for their work on this project. Maureen J. Lage and Michael Treglia were compensated by Eli Lilly and Company for their work on the project, while Joanne Lorraine, Magaly Perez-Nieves, Matthew D. Reaney, Angel Rodriguez, and Haya AscherSvanum, were employed by Eli Lilly and Company while working on this project. Eli Lilly and Company provided funding for all article processing fees.

Haya Ascher-Svanum was responsible for study design of this project. Maureen J. Lage and Michael Treglia were responsible for analyses. All authors contributed to the writing and review of the manuscript. Haya AscherSvanum is the guarantor for this manuscript. Maureen J. Lage is the corresponding author for this manuscript. All named authors meet the ICMJE criteria for authorship for this manuscript, take responsibility for the integrity of the work as a whole, and have given final approval for the version to be published.

Conflict of interest. Maureen J. Lage was compensated by Eli Lilly and Company for their work on this project. Michael Treglia was compensated by Eli Lilly and Company for their work on this project. Haya AscherSvanum, conducted this research as an employee and shareholder of Eli Lilly and Company. Magaly Perez conducted this research as an employee and shareholder of Eli Lilly and Company. Joanne Lorraine conducted this research as an employee and shareholder of Eli Lilly and Company. Matthew D. Reaney conducted this research as an employee and shareholder of Eli Lilly and Company. Angel Rodriguez conducted this research as an employee and shareholder of Eli Lilly and Company.

Compliance with ethics guidelines. The analysis in this article is based on existing data, and does not involve any new studies of human or animal subjects performed by any of the authors.

Open Access. This article is distributed under the terms of the Creative Commons Attribution Noncommercial License which permits any noncommercial use, distribution, and reproduction in any medium, provided the original author(s) and the source are credited.

\section{REFERENCES}

1. International Diabetes Foundation. IDF Diabetes Atlas. 6th ed; 2013. http://www.idf.org/sites/ default/files/EN_6E_Atlas_Full_0.pdf (last accessed Jan 26, 2014).

2. Boyle JP, Thompson TJ, Gregg EW, Barker LE, Williamson DF. Projection of the year 2050 burden of diabetes in the US adult population: dynamic modeling of incidence, mortality, and prediabetes prevalence. Popul Health Metrics. 2010;8:29.

3. American Diabetes Association. Economic costs of diabetes in the U.S. in 2012. Diabetes Care. 2013;36:1033-46.

4. Centers for Disease Control and Prevention. CDCfast facts on diabetes-2011 National Diabetes Fact Sheet-publications-diabetes DDT [Internet]. Centers for Disease Control and Prevention; 2013. http://www.cdc.gov/diabetes/pubs/factsheet11/ fastfacts.htm (last accessed Jan 26, 2014).

5. American Diabetes Association. Diagnosis and classification of diabetes mellitus. Diabetes Care. 2013;36(Suppl 1):S67-74. 
6. Kumar V, Abbas AK, Fausto N, Robbins SL, Cotran RS. Robbins and Cotran pathologic basis of disease. Philadelphia: Elsevier Saunders; 2005.

7. Nathan DM, Buse JB, Davidson MB, et al. Medical management of hyperglycemia in type 2 diabetes: a consensus algorithm for the initiation and adjustment of therapy: a consensus statement of the American Diabetes Association and the European Association for the Study of Diabetes. Diabetes Care. 2009;32:193-203.

8. Inzucchi SE, Bergenstal RM, Buse JB, et al. Management of hyperglycemia in type 2 diabetes: a patient-centered approach position statement of the American Diabetes Association (ADA) and the European Association for the Study of Diabetes (EASD). Diabetes Care. 2012;35:1364-79.

9. Nichols GA, Kimes TM, Harp JB, Kou TD, Brodovicz KG. Glycemic response and attainment of A1C goals following newly initiated insulin therapy for type 2 diabetes. Diabetes Care. 2012;35:495-7.

10. Oguz A, Benroubi M, Brismar K, et al. Clinical outcomes after 24 months of insulin therapy in patients with type 2 diabetes in five countries: results from the TREAT study. Curr Med Res Opin. 2013;29:911-20.

11. Boccuzzi SJ, Wogen J, Fox J, Sung JC, Shah AB, Kim J. Utilization of oral hypoglycemic agents in a druginsured U.S. population. Diabetes Care. 2001;24:1411-5.

12. Catalan VS, Couture JA, LeLorier J. Predictors of persistence of use of the novel antidiabetic agent acarbose. Arch Intern Med. 2001;161:1106-12.

13. D'Hoore W, Sicotte C, Tilquin C. Risk adjustment in outcome assessment: the Charlson comorbidity index. Methods Inf Med. 1993;32:382-7.

14. Quan H, Sundararajan V, Halfon P, Fong A, Burnand B, Luthi J-C, et al. Coding algorithms for defining comorbidities in ICD-9-CM and ICD-10 administrative data. Med Care. 2005;43:1130-9.

15. U.S. Bureau of Labor Statistics [Internet]. http://bls. gov/ (last accessed Jan 26, 2014).

16. Heckman JJ. Sample selection bias as a specification error. Econometrica. 1979;47:153-61.

17. Griswold M, Parmigiani G, Potoskey A, Lipscomb J. Analyzing health care costs: a comparison of statistical methods motivated by Medicare colorectal cancer charges. Biostatistics. 2004;1: $1-23$.

18. Halpern R, Becker L, Iqbal SU, Kazis LE, Macarios D, Badamgarav $\mathrm{E}$. The association of adherence to osteoporosis therapies with fracture, all-cause medical costs, and all-cause hospitalizations: a retrospective claims analysis of female health plan enrollees with osteoporosis. J Manag Care Pharm. 2011;17:25-39.

19. Brown JB, Nichols GA, Glauber HS, Bakst A. Tenyear follow-up of antidiabetic drug use, nonadherence, and mortality in a defined population with type 2 diabetes mellitus. Clin Ther. 1999;21:1045-57.

20. Rhee MK, Slocum W, Ziemer DC, et al. Patient adherence improves glycemic control. Diabetes Educ. 2005;31:240-50.

21. Gonzalez JS, Peyrot M, McCarl LA, et al. Depression and diabetes treatment nonadherence: a metaanalysis. Diabetes Care. 2008;31:2398-403.

22. Bogner HR, Morales KH, de Vries HF, Cappola AR. Integrated management of type 2 diabetes mellitus and depression treatment to improve medication adherence: a randomized controlled trial. Ann Fam Med. 2012;10:15-22.

23. Tunis SL, Ascher-Svanum H, Stensland M, Kinon BJ. Assessing the value of antipsychotics for treating schizophrenia: the importance of evaluating and interpreting the clinical significance of individual service costs. Pharmacoeconomics. 2004;22:1-8.

24. Balkrishnan R, Rajagopalan R, Camacho FT, Huston SA, Murray FT, Anderson RT. Predictors of medication adherence and associated health care costs in an older population with type 2 diabetes mellitus: a longitudinal cohort study. Clin Ther. 2003;25:2958-71.

25. Breitscheidel L, Stamenitis S, Dippel F-W, Schöffski O. Economic impact of compliance to treatment with antidiabetes medication in type 2 diabetes mellitus: a review paper. J Med Econ. 2010;13:8-15.

26. Cramer JA. A systematic review of adherence with medications for diabetes. Diabetes Care. 2004;27: 1218-24.

27. Currie CJ, Peyrot M, Morgan CL, et al. The impact of treatment noncompliance on mortality in people with type 2 diabetes. Diabetes Care. 2012;35:1279-84.

28. Ho P, Rumsfeld JS, Masoudi FA, et al. Effect of medication nonadherence on hospitalization and mortality among patients with diabetes mellitus. Arch Intern Med. 2006;166:1836-41.

29. Salas M, Hughes D, Zuluaga A, Vardeva K, Lebmeier M. Costs of medication nonadherence in patients with diabetes mellitus: a systematic review and critical analysis of the literature. Value Health. 2009;12:915-22. 